\title{
El mobbing o acoso moral en el trabajo: análisis del caso ecuatoriano
}

\section{Mobbing or moral harassment at work: the case of Ecuador}

\author{
Sánchez Sarmiento, Marcela Paz \\ Universidad Católica de Cuenca \\ Cuenca, 010101, Ecuador \\ msanchezs@ucacue.edu.ec
}

\begin{abstract}
Resumen
El presente trabajo analiza el mobbing o acoso moral desde una perspectiva vanguardista, enfocada al ámbito del derecho laboral ecuatoriano, a través de una investigación sobre los elementos, sujetos y características para aportar con ideas y conclusiones acerca de este tema actual y trascendental. Ante la falta de regulación del mobbing en nuestra legislación, se tratará de justificar la importancia de regularlo, de acuerdo al avance que demanda nuestra Constitución de la República del año 2008 (vigente), el mismo que debería ser un aspecto normado con especificidad ya que en la actualidad representa un atentado contra principios y derechos constitucionales principalmente como el de libertad, dignidad y no discriminación. Al ser un problema que no está regulado en nuestro ordenamiento jurídico, permite una serie de abusos que desencadenan conflictos que trascienden el ámbito laboral, llegando a afectar al individuo en su integridad, honorabilidad, salud mental y espiritual, que siendo derechos inherentes a su calidad de personas, comprometen hasta a la familia y al entorno en el que se desenvuelve. Es por ello que existe la imperiosa necesidad que este tema sea analizado y estudiado.
\end{abstract}

Palabras clave: acoso moral, mobbing, derecho laboral.

\begin{abstract}
This article analyzes the mobbing or moral harassment, from an avant-garde perspective, focused on the eld of the Ecuadorian labor law, through a research on the elements, individuals and characteristics; in order to contribute with ideas and conclusions about this current and highly important issue. Given the lack of mobbing regulations in our legislation; we will try to justify the importance of its normative, in accordance with the advance demanded by the Ecuadorian Constitution, which should be a specifically regulated aspect as it currently represents a threat against principles and constitutional rights like those of freedom, dignity and non-discrimination. This regulatory gap in our legal system, mobbing or moral harassment, allows a series of abuses that trigger conicts which transcend the workplace, affecting the individual in their integrity, honor, mental and spiritual health. Being these, inherent rights to their quality status as a person, they compromise even the family and the environment in which the individual interacts. This is why it is imperative that this topic be analyzed and studied.
\end{abstract}

Key words: mobbing, labor law.

\section{Definición, antecedentes y naturaleza jurídica}

El concepto de mobbing o acoso moral en sus inicios fue introducido por Konrad Lorenz quien utilizaba este término para definirlo como "el ataque de un grupo de animales pequeños que logra atemorizar a un animal más grande" (Ávila Molina, 2014). Luego fue Heinz Leymann quien desarrollo la idea del mobbing como se conoce en la actualidad: "la violencia psicológica, sistemática y recurrente que se genera a una o varias personas". Estas definiciones que nacerían dentro del campo de la psicología serían más tarde aplicadas dentro del campo del derecho laboral. El profesor Iñaki Piñuel y Zabala, catedrático de la Universidad de Alcalá de Henares, afirma que el mobbing o acoso laboral:
"Tiene como objetivo intimidar, apocar, reducir, aplanar, amedrentar y consumir emocional e intelectualmente a la víctima, con vistas a eliminarla de la organización o a satisfacer la necesidad insaciable de agredir, controlar y destruir que suele presentar el hostigador, que aprovecha el contexto que le brinda la situación organizativa particular (reorganización, reducción de costes, burocratización, cambios vertiginosos, etc.) para canalizar una serie de impulsos y tendencias psicopáticas" (Piñuel et al., 2001).

Según la Real Academia Española en el Diccionario de la Lengua Española "acosar" consiste en "perseguir, hostigar, importunar, molestar o asediar. Se trata, en definitiva, de conductas con las que se persigue perjudicialmente a 
una persona de manera insistente y continuada". El acoso laboral es conocido como acoso moral (que es el acoso psicológico en el trabajo) o a través del término inglés mobbing que significa: acosar, hostigar o acorralar en grupo. Se debe diferenciar con claridad el acoso moral o mobbing con el llamado Síndrome del quemado o burnout. En el primer caso se trata de una acción negativa u hostil en contra de un trabajador aislándolo del resto de los compañeros y lograr que en último término este abandone "voluntariamente" el trabajo; mientras que en el segundo caso, es un sentimiento de agotamiento físico, como lo define Herbert Freudenberger una "sensación de fracaso y una existencia agotada o gastada, que resulta de una sobrecarga por exigencias de energías, recursos personales y fuerza espiritual del trabajador" (Moreno-Jiménez et al., 2009). Para la psiquiatra y victimóloga francesa Marie-France Hirigoyen, el término acoso moral se utiliza para referirse a ciertas conductas de la vida cotidiana que constituyen una forma de violencia perversa, a un proceso de maltrato psicológico en el que un individuo puede destruir a otro sin ningún sentimiento de culpa (2000). En el campo laboral, el acoso moral es descrito como un proceso de maltrato psicológico mediante el cual un individuo puede hacer pedazos a otro y el ensañamiento puede conducir, incluso, a un verdadero asesinato psíquico. Se trata de cualquier manifestación de una conducta abusiva y, en especial, los comportamientos, palabras, actos, gestos y escritos que puedan atentar contra la personalidad, la dignidad o integridad física o psíquica de un individuo, o que puedan poner en peligro su empleo, o degradar el clima de trabajo.

Además, cuando el proceso de acoso se instaura, la víctima es estigmatizada: se dice que el trato con ella es difícil, que tiene mal carácter o que está loca. Se considera que su personalidad es la responsable de las consecuencias del conflicto y la gente se olvida de cómo era antes o de cómo es en otro contexto. Más aún, las víctimas, al principio y contrariamente a lo que los agresores pretenden hacer creer, no son personas afectadas de alguna patología o particularmente débiles. Al contrario, el acoso empieza cuando una víctima reacciona contra el autoritarismo de un superior y no se deja avasallar.

Para la citada autora, su capacidad de resistir a la autoridad a pesar de las presiones es lo que la señala como blanco. La empresa en su conjunto se puede convertir en un sistema perverso cuando el fin justifica los medios y cuando está dispuesta a todo -incluso a destruir a sus empleadoscon tal de alcanzar sus objetivos. En este caso, la mentira desencadena el proceso perverso en el mismo nivel de la organización del trabajo (Hirigoyen, 2000). Una de las definiciones que mejor describe el concepto de mobbing o acoso moral es la que nos indica Velásquez Fernández para quien: mobbing deriva del inglés mob, cuyo significado en castellano sería el de una multitud excitada que rodea o asedia a alguien (una persona) o a algo (un edificio, un objeto), bien sea de forma amistosa u hostil. El sustantivo $m o b$ es gentío, el vulgo, la plebe, el populacho, mientras que el verbo to $m o b$ indica la acción de ese gentío de agolparse o atestarse en torno a algo o bien asediar o atacar en masa a alguien. El origen de la palabra, describe una acción colectiva de un grupo de personas frente a algo o a alguien $\mathrm{y}$, curiosamente, no siempre de modo negativo, tal como ahora está siendo tratada en el ámbito de las condiciones de trabajo (Vázquez, 2015). La Comisión Europea, definió el 14 de mayo de 2001 al mobbing, como un comportamiento negativo entre compañeros o entre superiores e inferiores jerárquicos, a causa del cual el afectado es objeto de acoso y ataques sistemáticos y durante mucho tiempo, de modo directo o indirecto, por parte de una o más personas, con el objetivo y/o el efecto de hacerle el vacío.

El mobbing se desarrolla dentro del contexto del o los trabajadores indeseados dentro de un lugar de trabajo sea tanto en el sector público como en el privado. En general, consiste en un continuado, deliberado y degradante maltrato verbal y modal que recibe un trabajador por parte de otro u otros compañeros, subordinados o jefes que se comportan con él de forma cruel con vistas a lograr su aniquilación o destrucción psicológica y a obtener así su salida de la organización a través de diferentes modalidades ilícitas (Piñuel et al., 2003). Así, la definición de acoso moral dependerá del elemento subjetivo intencional, esto es, la aniquilación interna del individuo y su salida de la institución, de no existir este elemento, no estaríamos ante la figura del mobbing o acoso moral.

En la actualidad, las instituciones tanto públicas como privadas, no se encuentran preparadas del todo para afrontar una situación de acoso moral o mobbing, por lo que la mayoría de las veces, ni la reconocen, llegando incluso a despedir a la víctima de acoso por considerarla molesta y poco apta para el puesto de trabajo, empeorando así su situación laboral, social, familiar e incluso psicológica por el daño que la misma provoca en sus víctimas.

A nivel internacional numerosos países han reconocido el problema del acoso moral o mobbing, regulándolo en la legislación dentro del campo de la salud y seguridad. Argentina, Bélgica, Canadá, Finlandia, Francia, Polonia y Suecia adoptaron recientemente nuevas leyes o enmendaron las normativas existentes para abordar la violencia en el trabajo. En Ecuador la legislación no ha definido hasta el día de hoy las prácticas de mobbing o acoso moral en forma directa por lo tanto no existen normas que traten el problema.

\section{Características del acoso moral o mobbing}

El mobbing o acoso moral se inicia a través de las relaciones interpersonales que se crean dentro del trabajo y por la relación jurídica que existe entre el trabajador y el empleador en relación al contrato de trabajo suscrito entre los mismos. Debemos recalcar que el cambio de actitud hacia el trabajador inicia por un hecho puntual y es este el que va desencadenando el acoso y estigmatización de la o las víctimas, sin que exista ninguna conducta de compasión 
por parte del acosador o de rebeldía por parte de la o las víctimas.

Además, cabe acotar que estas acciones de hostigamiento no son momentáneas, aparecen al menos durante seis meses y con frecuencia son semanales con el fin de arrastrar a la o las víctimas a una posición de indefensión generando efectos negativos a su salud mental, lo cual crea un ambiente hostil con relación al sufrimiento, miedo acentuado y continuo, un sentimiento de amenaza.

Para poder delimitar el concepto de mobbing o acoso moral, señalaremos las características más destacadas y estas son:

- El aislamiento paulatino del trabajador, y el uso de medidas exclusivas contra él o excluyéndolo en la medida de lo posible del resto de sus compañeros de trabajo, quitándole al trabajador áreas de responsabilidad, o al contrario sobrecargándolo con la asignación de tareas o reduciéndole los plazos de ejecución de sus tareas de forma sistemática, induciéndolo a que cometa errores, hace que se deteriore su rendimiento en el trabajo.

- La falta de comunicación con la víctima, el empleador le limita las posibilidades de comunicarse al tener actitudes como ignorarle hablando solo a una tercera persona presente, simulando su no existencia, reduciéndole así sus posibilidades de expresarse con sus compañeros o jefes.

- Difamar a la víctima, mediante la propagación de rumores infundados o críticas públicas que menoscaben su reputación, ya sea profesional o personalmente obligándolo a hacer mal su trabajo, de manera que se inicia un bloqueo al desarrollo profesional del trabajador.

- Se trata de un conflicto asimétrico. La parte hostigadora tiene más recursos, apoyos o una posición superior a la de la víctima. El agresor o agresores se revisten de algún argumento de poder como puede ser la superioridad jerárquica, la fuerza física, popularidad.

- Contínuo clima de degradación y humillación.

Estas son las características comunes en el mobbing o acoso moral, aunque podrían variar según la persona o las circunstancias en las que se presenten, sin embargo, lo común en todas las víctimas de este fenómeno es la existencia del daño psicológico y físico que imposibilita a la persona a reintegrarse dentro de un puesto de trabajo, y demuestra el daño inminente que causa en las personas que lo sufren, lo que hace necesario una regulación en la normativa actual.

\section{Elementos esenciales del acoso moral o mobbing}

Para que el mobbing o acoso moral se constituya como tal tiene que haber la concurrencia de algunos elementos, caso contrario se configuraría cualquier otra figura como el burnout o Síndrome del quemado ${ }^{1}$, o estrés laboral que tienen características similares pero que varían en cuanto

${ }^{1}$ El Síndrome del quemado o burnout se define como: agotamiento emocional, despersonalización o deshumanización y falta de realización personal en el trabajo sus consecuencias a corto o largo plazo y los sujetos que intervienen.

\subsection{Sujetos que intervienen en el acoso moral o mobbing}

Los sujetos que intervienen son:

Sujeto activo: Según Rodríguez López define a estas personas como:

"resentidas, frustradas, envidiosas, celosas o egoístas, teniendo uno, o varios o todos estos rasgos en mayor o menor medida. Están necesitadas de admiración, reconocimiento y protagonismo y lo que quieren es figurar, ascender o aparentar, aun cuando simplemente deseen hacer daño o anular a otra persona" (López, 2004)

El sujeto activo puede variar de persona en persona, puede ser de un jerárquico superior el que se vea acosado u hostigado por sus subordinados, esta situación puede presentarse cuando los subordinados no comparten las ideas de mando que este utiliza al momento de tomar sus decisiones dentro de la empresa, o cuando este es ascendido de puesto dentro de la empresa generando envidias con sus antiguos compañeros; pueden presentarse diferentes casos entre colegas, esto sucede cuando en el equipo de trabajo no pueden soportar la diferencia en su grupo, como en el caso que explica la doctora Hirigoyen:

"Cuando la mujer accede a determinadas corporaciones que han estado tradicionalmente ocupadas por hombres, no le resulta fácil hacerse respetar. Debe soportar bromas groseras, gestos obscenos, que se desprecie todo lo que pueda decir, y que no se tome en serio su trabajo. Todo ello parece una «novatada» y todo el mundo se ríe, inclusive las mujeres presentes. No tienen otra elección" (Hirigoyen, 2000).

Otro que puede presentarse es el "típico" caso de mobbing que es el acoso por parte de los superiores hacia los subordinados. Las motivaciones varían según el sujeto activo que las lleve a cabo, ya sea por justificarse por fallas cometidas en el ejercicio de su trabajo, por venganza, por envidias, etc., pero su única finalidad será presionar a la víctima a su salida "voluntaria" de la empresa.

Sujeto pasivo: Las víctimas son principalmente grupos vulnerables de la sociedad, y él se siente indefenso, hostigado y agredido por el sujeto activo de la relación interpersonal; por lo que no existe en realidad un perfil psicológico manifiesto. Entre las principales víctimas de este tipo de acoso tenemos: mujeres que son vistas como una competencia, ocupando puestos que antes pertenecían solo a hombres siendo consideradas como una amenaza en muchas empresas y cargos en el sector público. Lo mismo podemos decir de personas con discapacidad e incluso los adultos mayores.

\section{Consecuencias del acoso moral o mobbing}

Las consecuencias sobre la víctima de este problema son, a largo plazo, sobre todo en la salud de la víctima 
dependiendo de la duración del acoso, su intensidad y la vulnerabilidad de la víctima (vivencias familiares, experiencias anteriores, etc).

Se deben analizar sus consecuencias desde diferentes aspectos y efectos que este produce.

a. Efectos sobre la víctima. - Al pasar del tiempo, la víctima puede llegar a tener un sentimiento de desvalorización y falta de autoestima, que incluso pueden dejar secuelas físicas como hipertensión arterial, úlcera gastroduodenal, daños del sistema nervioso, problemas cardíacos, tensión arterial y psíquicas como ansiedad, depresión, que afectan el ejercicio de las funciones del trabajador dentro de su lugar de trabajo.

En el ámbito familiar. - La víctima descarga su frustración y amargura con su familia afectando así las relaciones familiares. Debemos entender que el acoso o mobbing interfiere de forma directa con la vida normal y productiva del individuo; la familia a su vez padecerá las consecuencias de tener cerca a una persona amargada, desmotivada, sin ganas de trabajar, por lo que es común que se presenten casos de violencia intrafamiliar, alcoholismo, drogadicción, divorcios y a veces puede llevar al suicido de la víctima de acoso.

En el ámbito social.- Es posible que estos individuos lleguen a ser muy susceptibles e hipersensibles a la crítica, con actitudes de desconfianza y con conductas de aislamiento, evitación, retraimiento o, por otra parte, de agresividad $\mathrm{u}$ hostilidad y con otras manifestaciones de inadaptación social. Son comunes sentimientos de ira y rencor, y deseos de venganza contra el/los agresor/es. En general, puede decirse que la salud social del individuo se encuentra en profundidad afectada, pues este problema puede distorsionar las interacciones que tiene con otras personas e interferir en su vida normal y productiva del individuo. De igual modo se verá más afectada cuanto menores apoyos efectivos encuentre "personas que le provean de afecto, comprensión, consejo, ayuda (...) tanto en el ámbito laboral como en el extra laboral" (Torrecillas, 2014).

b. Efectos de la víctima en el ámbito laboral y para la empresa.- La empresa en la que se produce el mobbing deja su huella a través de las diferentes conductas entre los trabajadores que lo padecen. Entre ellas cabe citar: un aumento de absentismo, tanto justificado por bajas de enfermedad como no justificado, falta de puntualidad, baja calidad en la atención al cliente, decremento de la productividad, rotación de puestos; y resultarán individuos desmotivados e insatisfechos que encontrarán el trabajo como un ambiente hostil asociado al sufrimiento y que no tendrán un óptimo rendimiento en el ejercicio de sus funciones en la empresa y por ende se afecta el rendimiento de la empresa, el cambio de personal trae consigo además altos costos en capacitaciones, lo que perjudica de manera inminente el crecimiento económico de la empresa.

Se dice que en casos extremos el mobbing puede llevar a un trabajador a un estado de incapacidad permanente del cual su recuperación definitiva puede durar años $\mathrm{y}$ en ciertos casos, no volver a recuperar nunca su capacidad de trabajo.

5 El mobbing o acoso moral en el ordenamiento jurídico ecuatoriano vigente $\mathrm{y}$ otras legislaciones

\subsection{Principios de aplicación en relación al mobbing o acoso moral}

En la Constitución de la República del Ecuador (2008) se evidencia a uno de los mejores instrumentos legales que en materia de garantía de derechos humanos existe, como se expresa en los siguientes artículos:

Art. 3. "Son deberes primordiales del Estado: 1. Garantizar sin discriminación alguna el efectivo goce de los derechos establecidos en la Constitución y en los instrumentos internacionales...".

Art. 11. "El ejercicio de los derechos se regirá por los siguientes principios: 9. El más alto deber del Estado consiste en respetar y hacer respetar los derechos garantizados en la Constitución".

Así, los derechos a la igualdad, no discriminación, integridad moral, de libertad de expresión, información, al honor, a la intimidad, a la propia imagen, libertad ideológica, religiosa, de reunión y de tutela judicial que hacen del ciudadano "persona" tienen que poder ejercerse también en el ámbito laboral.

\subsubsection{Principios constitucionales laborales}

Haciendo una muy breve síntesis de los preceptos constitucionales en materia de garantías, en el Estado constitucional de derechos y justicia, y que a su vez sirven de soporte constitucional al objeto del estudio de este trabajo se pueden destacar a los siguientes, respecto de los cuales, luego de la transcripción, se formularán algunos planteamientos:

Art. 66. Se reconoce y garantizará a las personas: 2. El derecho a una vida digna, que asegure la salud, alimentación y nutrición, agua potable, vivienda, saneamiento ambiental, educación, trabajo, empleo, descanso y ocio, cultura física, vestido, seguridad social y otros servicios sociales necesarios. 3 . El derecho a la integridad personal, que incluye: 4 . Derecho a la igualdad formal, igualdad material y no discriminación. 5. El derecho al libre desarrollo de la personalidad, sin más limitaciones que los derechos de los demás. 6. El derecho a opinar y expresar su pensamiento libremente $\mathrm{y}$ en todas sus formas y manifestaciones. 17. EI derecho a la libertad de trabajo. Nadie será obligado a realizar un trabajo gratuito o forzoso, salvo los casos que determine la ley. 18. El derecho al honor y al buen nombre. La ley protegerá la imagen y la voz de la persona.

Art. 83. Son deberes y responsabilidades de las ecuatorianas y los ecuatorianos, sin perjuicio de otros previstos 
en la Constitución y la ley: 5. Respetar los derechos humanos y luchar por su cumplimiento. 12. Ejercer la profesión u oficio con sujeción a la ética.

Art. 230. En el ejercicio del servicio público se prohíbe, además de lo que determine la ley: 3 . Las acciones de discriminación de cualquier tipo.

Art. 277. Para la consecución del buen vivir, serán deberes generales del Estado: 1. Garantizar los derechos de las personas, las colectividades y la naturaleza.

Art. 326. El derecho al trabajo se sustenta en los siguientes principios: 3. En caso de duda sobre el alcance de las disposiciones legales, reglamentarias o contractuales en materia laboral, estas se aplicarán en el sentido más favorable a las personas trabajadoras. 5. Toda persona tendrá derecho a desarrollar sus labores en un ambiente adecuado y propicio, que garantice su salud, integridad, seguridad, higiene y bienestar. 6 . Toda persona rehabilitada después de un accidente de trabajo o enfermedad, tendrá derecho a ser reintegrada al trabajo y a mantener la relación laboral, de acuerdo con la ley. 11. Será válida la transacción en materia laboral siempre que no implique renuncia de derechos y se celebre ante autoridad administrativa o juez competente.

Art. 329. Inciso Primero.- Las jóvenes y los jóvenes tendrán el derecho de ser sujetos activos en la producción, así como en las labores de auto sustento, cuidado familiar e iniciativas comunitarias. Se impulsarán condiciones y oportunidades con este fin. Inciso Cuarto.Los procesos de selección, contratación y promoción laboral se basarán en requisitos de habilidades, destrezas, formación, méritos y capacidades. Se prohíbe el uso de criterios e instrumentos discriminatorios que afecten la privacidad, la dignidad e integridad de las personas.

Art. 331. El Estado garantizará a las mujeres igualdad en el acceso al empleo, a la formación y promoción laboral y profesional, a la remuneración equitativa, y a la iniciativa de trabajo autónomo. Se adoptarán todas las medidas necesarias para eliminar las desigualdades. Se prohíbe toda forma de discriminación, acoso o acto de violencia de cualquier índole, sea directa o indirecta, que afecte a las mujeres en el trabajo.

Art. 341. El Estado generará las condiciones para la protección integral de sus habitantes a lo largo de sus vidas, que aseguren los derechos y principios reconocidos en la Constitución, en particular la igualdad en la diversidad y la no discriminación, y priorizará su acción hacia aquellos grupos que requieran consideración especial por la persistencia de desigualdades, exclusión, discriminación o violencia, o en virtud de su condición etaria, de salud o de discapacidad.

Art. 393. El Estado garantizará la seguridad humana a través de políticas y acciones integradas, para asegurar la convivencia pacífica de las personas, promover una cultura de paz y prevenir las formas de violencia y discriminación y la comisión de infracciones y deli- tos. La planificación y aplicación de estas políticas se encargará a órganos especializados en los diferentes niveles de gobierno.

De los artículos transcritos podemos manifestar que, en relación al acoso moral o mobbing, se configura una violación a los derechos constitucionales de la persona que limita el libre desarrollo de la personalidad; además, es totalmente incompatible con el carácter garantista de nuestra Constitución, puesto que la dignidad e integridad personal constituyen derechos fundamentales e inherentes a la naturaleza del ser humano, cabe destacar que en la Constitución se considera al trabajador tanto por esa calidad cuanto como ciudadano.

Como señala Alegre Martínez, "la dignidad humana consistiría en la característica propia e inseparable de toda persona en virtud de su racionalidad -independiente del momento y por encima de las circunstancias en que se desenvuelva su vida- que se materializa en la realización, desarrollo y perfección de la propia personalidad, a través del ejercicio de los derechos inviolables e irrenunciables que le son inherentes" (1995); por consiguiente debemos entenderlo no como la única protección a los derechos fundamentales en el ámbito laboral, sino en el contexto de las realidades que se presenten dentro del ámbito protegido de un derecho fundamental, más concretizado en este caso a la luz de los valores y principios constitucionales. Siguiendo a Fernández López, al abordar la cuestión del mobbing desde la perspectiva de la mera tutela de la dignidad del trabajador, siendo crucial como valor jurídico a proteger, presenta hoy entre nosotros riesgos innegables de desestimación judicial, de ahí que fuera necesario buscar caminos alternativos, que reforzarán la posición de los trabajadores afectados por criticables que, en principio, puedan ser las bases de los pronunciamientos judiciales (2002); por la afectación directa de la promoción y formación profesional del derecho del trabajador.

En cuanto a la integridad personal, esta junto con la existencia de la persona natural, se constituyen en un presupuesto para la existencia de los bienes jurídicos que la sociedad reconoce y garantiza a sus asociados, porque la vida humana, su integridad material y moral, es el supremo bien jurídico; en el caso del acoso moral se revela siempre y en todo caso, y de forma primaria, como agresión al estado de salud del trabajador-víctima, con importantísimos efectos negativos o perjudiciales en su equilibrio emocional y psíquico, multiplicando de modo exponencial las enfermedades psicosomáticas y el riesgo de accidentes. También resulta afectado el respeto de su honra o el derecho al honor -tanto en su faceta personal como profesional- ya que el acoso moral comprende, o puede comprender, conductas atentatorias tanto contra la autoestima como contra la reputación de la víctima, por lo general, en grados extremos -por ejemplo, ridiculización colectiva o pública, "ninguneo", indiferencia, marginación, continuas recriminaciones por pretendidos malos resultados, acusaciones insidiosas reiteradas- así como actuaciones dirigidas a desconsiderar, 
ignorar e invalidar su actividad laboral. En consecuencia, pocas dudas pueden caber respecto a su negativa afectación del derecho al honor. Representa, pues, una forma sistemática y extrema de "aniquilamiento" de la esfera profesional del trabajador con pretensiones de proyección exterior y hacia el futuro, rebajando hasta la humillación la consideración debida a la valía profesional del trabajador. De ahí que en determinados estudios se insista en calificar tal conducta como una forma de perversión cuyas manifestaciones contienen un alcance lesivo de proyección impredecible e implican asimismo la desacreditación, el aislamiento y la confusión totales del trabajador-víctima, con la consiguiente ruptura de sus vínculos sociales y de grupo y, a veces, incluso los familiares (Barbado, 2004). De lo expuesto resulta indispensable una adecuada regulación jurídica encaminada a evitar conductas lesivas.

\subsubsection{Normativa de la ley de seguridad social}

El acoso moral o mobbing como se expuso en líneas anteriores, no se encuentra regulado en el Código del Trabajo ni tampoco en Ley Orgánica para la justicia laboral y reconocimiento del trabajo en el hogar; por lo que, debemos remitirnos también a leyes que regulan la situación, del trabajador en otros aspectos como la seguridad social, al efecto, la Constitución de la Repùblica (2008) en su Art. 32, inciso primero.- La salud es un derecho que garantiza el Estado, cuya realización se vincula al ejercicio de otros derechos, entre ellos el derecho al agua, la alimentación, la educación, la cultura física, el trabajo, la seguridad social, los ambientes sanos y otros qeu sustentan el Buen Vivir...; y en concordancia con lo que dispone la Ley de Seguridad Social (2006) en sus artículos:

Art. 2. Inciso primero- Son sujetos obligados a solicitar la protección del Seguro General Obligatorio, en calidad de afiliados, todas las personas que perciben ingresos por la ejecución de una obra o la prestación de un servicio físico o intelectual, con relación laboral o sin ella (...).

Art. 3. El Seguro General Obligatorio protegerá a sus afiliados obligados contra las contingencias que afecten su capacidad de trabajo y la obtención de un ingreso acorde con su actividad habitual, en casos de:

- Enfermedad;

- Maternidad;

- Riesgos del trabajo;

- Vejez, muerte, e invalidez, que incluye discapacidad; $\mathrm{y}$,

- Cesantía.

El Seguro Social Campesino ofrecerá prestaciones de salud y, que incluye maternidad, a sus afiliados, y protegerá al Jefe de familia contra las contingencias de vejez, muerte, e invalidez, que incluye discapacidad. Para los efectos del Seguro General Obligatorio, la protección contra la contingencia de discapacidad se cumplirá a través del seguro de invalidez.
El Estado tiene la responsabilidad de velar por el completo bienestar del trabajador dentro de su entorno laboral el cual implica además su salud psíquica; y, al ser el mobbing un tipo de violencia, tiene una característica diferencial respecto de otras formas de violencia que se presentan en el ámbito laboral, que es la de no dejar rastro ni señales externas a no ser por el deterioro progresivo de la víctima, que suele ser atribuido intencionalmente a otras causas, tales como problemas de relación, de personalidad, carácter difícil o bien incompetencia profesional que debería regularse dentro del grupo de los llamados riesgos laborales, entendidos como la posibilidad de que un trabajador sufra un determinado daño derivado del trabajo. El riesgo laboral se denominará grave o inminente cuando la posibilidad de que se materialice en un accidente de trabajo es alta y las consecuencias presumiblemente severas o importantes. Sin embargo, son los que menor tratamiento han tenido hasta ahora en nuestro ordenamiento jurídico, pues la salud en el trabajo comprende no solo la parte física sino psíquica del trabajador y por lo tanto constituye un derecho fundamental que debe ser reconocido y garantizado así como lo dispone la Constitución de Montecristi en el capítulo II Sección Octava de Trabajo y seguridad social; en sus artículos:

Art. 33. El trabajo es un derecho y un deber social, y un derecho económico, fuente de realización personal y base de la economía. El Estado garantizará a las personas trabajadoras el pleno respeto a su dignidad, una vida decorosa, remuneraciones y retribuciones justas y el desempeño de un trabajo saludable y libremente escogido o aceptado.

Art. 34. El derecho a la seguridad social es un derecho irrenunciable de todas las personas, y será deber y responsabilidad primordial del Estado.

La seguridad social se regirá por los principios de solidaridad, obligatoriedad, universalidad, equidad, eficiencia, subsidiaridad, suficiencia, transparencia y participación, para la atención de las necesidades individuales y colectivas.

El Estado garantizará y hará efectivo el ejercicio pleno del derecho a la Seguridad social, que incluye a las personas que realizan trabajo no remunerado en los hogares, actividades para el auto sustento en el campo, toda forma de trabajo autónomo y a quienes se encuentran en situación de desempleo.

Tanto en la Constitución como en la Ley de Seguridad Social, se contempla la protección de todo trabajador sea cual fuere su situación y en la circunstancias ya enumeradas, y al ser así debería regularse este fenómeno de acoso moral dentro de los llamados riesgos de trabajo ya que implica una violencia de tipo sicológico que frena el desarrollo del trabajador y que incluso podría considerarse una amenaza para la salud pública, por tanto estimo que el Estado debe prevenir y controlar este tipo de violencia que significa un freno a la gestión pública y resquebrajamiento del sistema democrático y del Estado de Derecho, por cuanto afecta, en definitiva, valores como la libertad, la 
justicia y la igualdad.

\subsubsection{Normativa contenida en convenios y tratados inter- nacionales}

La Declaración Universal de Derechos Humanos, adoptada y proclamada por la Asamblea General de las Naciones Unidas en su resolución 217 A (III), de 10 de diciembre de 1948, es la cuna de los preceptos legales aplicables a los casos de mobbing, tal y como se observa en los siguientes artículos de la misma:

Art. 1. Todos los seres humanos nacen libres e iguales en dignidad y derechos y, dotados como están de razón y conciencia, deben comportarse fraternalmente los unos con los otros.

Art. 3. Todo individuo tiene derecho a la vida, a la libertad y a la seguridad de su persona.

Art. 5. Nadie será sometido a torturas ni a penas o tratos crueles, inhumanos o degradantes.

Art. 12. Nadie será objeto de injerencias arbitrarias en su vida privada, su familia, su domicilio o su correspondencia, ni de ataques a su honra o a su reputación. Toda persona tiene derecho a la protección de la ley contra tales injerencias o ataques.

En la Declaración Americana de los Derechos y Deberes del Hombre se dispone que toda persona tenga derecho al trabajo en condiciones dignas. Por su parte, el Art. 5, inciso 1, de la Convención Americana de Derechos Humanos (Pacto de San José de Costa Rica) establece que toda persona tiene derecho a que se respete su integridad física, psíquica y moral y agrega, en el inciso 2, que nadie debe ser sometido a tratos crueles, inhumanos o degradantes; en el artículo 11 se estatuye expresamente que toda persona tiene derecho al respeto de su honra y al reconocimiento de su dignidad.

Por otro lado, la Convención contra la tortura y otros tratos o penas crueles, inhumanos o degradantes dispone:

Art. 16. Todo Estado Parte se comprometerá a prohibir en cualquier territorio bajo su jurisdicción otros actos que constituyan tratos o penas crueles, inhumanos o degradantes y que no lleguen a ser tortura tal como se define en el Art. 1, cuando esos actos sean cometidos por un funcionario público y otra persona que actúe en el ejercicio de las funciones oficiales, o por instigación o con el consentimiento o la aquiescencia de tal funcionario o personal.

Igualmente, el Pacto Internacional de Derechos Económicos, Sociales y Culturales en su Art. 6 establece que el Estado debe garantizar el derecho de toda persona de ganarse la vida mediante un trabajo, tomando todas las medidas necesarias para ello, en particular, para que tenga una ocupación plena y efectiva, con condiciones que garanticen las libertades políticas y económicas fundamentales de la persona humana. Los puntos mencionados, tienen que ser considerados en relación con lo que dispone el Artículo 66 numeral 3 literal a) de la Constitución de la República: Se reconoce y garantizará a las personas (...) el derecho a la integridad personal, que incluye: a) La integridad física, psíquica, moral y sexual.

\subsubsection{Posición de la OIT en relación al acoso moral en el ámbito laboral}

La Organización Internacional del Trabajo tiende una mano a las personas acosadas en la Carta de Principios Fundamentales de los ordenamientos laborales de 1998. La OIT publica periódicamente informes y estudios sobre las condiciones de trabajo (la última data del año 2001) que sirven para ayudar a la aplicación de las normas.

Un ejemplo claro de la involucración de la OIT con el problema del acoso psicológico en el trabajo, es el Convenio Colectivo adoptado por la Oficina Internacional del Trabajo y el sindicato de la OIT. Se firmó en Ginebra el 26 de febrero de 2001, en un intento de mejorar la calidad de las estructuras y procedimientos de prevención del acoso y solución del conflicto, tomando en consideración las normas internacionales del trabajo pertinentes y la Declaración de la OIT relativa a los principios y derechos fundamentales en el trabajo.

En el informe sobre la violencia en el trabajo del año 1998, realizado por Vittorio Di Martino, experto internacional en problemas de stress y violencia en el trabajo, y por Duncan Chappell, ex presidente de la Revista de Salud Mental de New South Wales, en Australia, y del Tribunal Arbitral del Commonwealth, en el Reino Unido: "La intimidación, el acoso, el hostigamiento y otras conductas similares pueden ser tan dañinos como la pura y simple violencia física", dicen los autores. "La inestabilidad de muchos tipos de empleos que es característica en estos tiempos genera enormes presiones en el lugar de trabajo, y vemos que estos signos de violencia aparecen cada vez con más frecuencia”.

Así la OIT también es consciente de que este fenómeno no afecta solo a los trabajadores sino a todo su entorno, en el caso del trabajo propiamente dicho la empresa ve afectado el ambiente que se genera y en costos por las indemnizaciones, nuevo personal y las pérdidas económicas, Vittorio Di Martino y Duncan Chappell acotan: Observa una conciencia creciente de que la violencia en el lugar de trabajo no es un fenómeno episódico e individual, sino un problema enraizado en factores más amplios, de orden social, económico organizativo y cultural. La violencia en el trabajo quiebra la funcionalidad del lugar del trabajo, y cualquier acción que se adopte contra ella se insertará en el desarrollo organizativo de una buena empresa (Serantes and Suárez, 2005).

La OIT también adoptó algunos Convenios sobre la protección de los trabajadores y la dignidad en el trabajo. En el año 2004, fue publicado un Repertorio de recomendaciones prácticas sobre la violencia en el trabajo en el sector de servicios y medidas para combatir este fenómeno de la OIT que aborda la difusión y la gravedad de los actos de violencia en los sectores de servicios e industria. Por otra parte la OIT, junto con organizaciones como el Consejo 
Internacional de Enfermería, la Organización Mundial de la Salud e Internacional de Servicios Públicos, desarrollaron una serie de directrices para combatir la violencia en el trabajo en el sector de la salud.

En el Proyecto de Convenio sobre el marco promocional para la salud y seguridad en el trabajo de la Conferencia General de la OIT, convocada en Ginebra por el Consejo de Administración de la Oficina Internacional del Trabajo, en su 95 reunión del 31 de mayo del 2006, trata de regular la seguridad y salud en el trabajo y el medio ambiente laboral, todos temas importantes al momento de la prevención del hostigamiento. El objetivo claro de este convenio se encuentra especificado en los siguientes artículos:

Art. 2.1. Todo miembro que ratifique el presente Convenio deberá promover la mejora continua de la seguridad y salud en el trabajo con el fin de prevenir, las lesiones, enfermedades y muertes ocasionadas por el trabajo mediante el desarrollo de una política, un sistema y un programa nacionales, en consulta con las organizaciones más representativas de empleadores y trabajadores.

Art. 2.2. Todo miembro deberá adoptar medidas activas con miras a conseguir en forma progresiva un medio ambiente de trabajo seguro y saludable mediante un sistema nacional y programas nacionales de seguridad y salud en el trabajo, teniendo en cuenta los principios recogidos en los instrumentos de la Organización Internacional de Trabajo (OIT) pertinentes para el marco promocional para la seguridad y salud en el trabajo (Chappell and Di Martino, 2006).

De lo expuesto podemos apreciar que el objetivo que tiene la OIT es promover un verdadero reconocimiento de los derechos de los trabajadores en cuanto su salud y seguridad, dentro de un medio ambiente sano en el que el trabajador pueda desenvolverse profesionalmente; esto a través de la participación activa del Estado en la que se adopte estrategias de prevención efectiva para prevenir la vulneración de este derecho.

\section{Conclusiones}

La necesidad de abordar el problema del acoso moral o mobbing es la de demostrar la importancia del por qué debería ser regulado en nuestra normativa actual al ser el Ecuador un estado de derechos y justicia, y en el que debe reconocerse y garantizarse los derechos fundamentales del trabajador que muchas veces son vulnerados tanto en el sector público como privado. No obstante, las principales secuelas y efectos del mobbing son los daños de tipo social y profesional, ya que el bien jurídico protegido reside en la esfera misma de la dignidad personal del trabajador.

Se debe entender que el acoso moral o mobbing es una agresión psicológica que supone un hecho premeditado y voluntario por parte del agente causante en una relación interpersonal, por ser una relación asimétrica, y que incide de forma directa sobre la conducta del trabajador sea o no un "mal trabajador", cuyas consecuencias es una violencia manifiesta en su entorno laboral, familiar y social, por lo que los daños sicológicos son a largo plazo.

En el caso de nuestro ordenamiento jurídico no existe todavía ningún tratamiento específico sobre el acoso moral y es más, no se ha dado un verdadero reconocimiento y protección de los derechos del trabajador - ciudadano, que se refieren a su personalidad moral, considerado como un derecho fundamental que la propia Constitución les reconoce, sin embargo tenemos normas legales cuyo alcance genérico nos permitiría afrontar este tipo de situaciones siempre y cuando esclarezcamos debidamente su alcance y significación.

Debido a la escasa y contradictoria jurisprudencia que existe en nuestro país, así como la falta de estudios serios sobre el tema han dificultado aún más el desarrollo de esta rama del derecho. El desconocimiento del tema por parte de los administradores de justicia, salvo pocas excepciones, y en otros casos gracias a la corrupción imperante en algunos de los órganos jurisdiccionales ha ocasionado que este problema no sea visibilizado ni por la legislación ni por la jurisprudencia correspondiente.

\section{Referencias}

Alegre, M. Á. M. (1995). El artículo 10.1 de la constitución como deber genérico de respetar la dignidad y los derechos de la persona. Revista general de derecho, (604):189-221.

Ávila Molina, D. V. (2014). Propuesta de reforma para establecer el acoso laboral en el código de trabajo.

Barbado, P. (2004). El acoso psicológico en el ámbito laboral ("mobbing"). su tratamiento en la jurisprudencia española. Revista de Jurisprudencia Argentina, (15): 15

Chappell, D. and Di Martino, V. (2006). Violencia en el Trabajo. Ginebra: Organización Internacional del Trabajo, 2da. Edición.

Constitucional, T. (2008). Constitución de la república del ecuador. Quito-Ecuador: Registro Oficial, 449:20-10.

de Seguridad Social, L. (2006). Corporación de estudios y publicaciones. Ecuador.

Hirigoyen, M.-F. (2000). Acoso Moral. Barcelona: Paidós.

López, M. F. F. (2002). El acoso moral en el trabajo $i$ una nueva fórmula de discriminación? Revista de derecho social, (19):53-76.

López, P. R. (2004). El acoso moral en el trabajo. Dijusa. Moreno-Jiménez, B., Garrosa Hernández, E., Rodríguez Carvajal, R., Martínez Gamarra, M., and Ferrer Puig, R. (2009). El burnout del profesorado universitario y las intenciones de abandono: un estudio multimuestra. Revista de Psicología del Trabajo y de las Organizaciones, 25(2):149-163.

Piñuel, I. et al. (2001). Mobbing: Cómo sobrevivir al acoso psicológico en el trabajo, volume 67. Editorial Sal Terrae.

Piñuel, I. et al. (2003). Mobbing: manual de autoayuda: 
claves para reconocer y superar el acoso en el trabajo. Madrid: Aguilar.

Serantes, N. P. and Suárez, M. A. (2005). Mitos en violencia laboral. Revista universitaria de ciencias del trabajo, (6):345-357.
Torrecillas, J. L. G. (2014). Patología psicosocial de origen laboral. Ciencia Forense, 167:167.

Vázquez, S. N. (2015). Cómo se pretende legislar el mobbing o acoso psicológico laboral en méxico.

Recibido: 14 de junio de 2016

Aceptado: 10 de abril de 2017

Sánchez Sarmiento, Marcela Paz: Abogada de los Tribunales de Justicia de la República y Licenciada en Ciencias Políticas y Sociales por la Universidad de Cuenca, Magister en Derecho Procesal por la Universidad Andina Simón Bolivar sede Ecuador, Docente tiempo completo de la Universidad Católica de Cuenca. 
